\title{
A ADVOCACIA
}

Discurso do Dr. João Monteiro na sessão magna do Instituto dos Adyogados de S. Paulo, em 7 de Setembro de 1897

\section{Meus Senhores:}

O nosso erudito e honrado presidente Dr. João Mendes de Almeida, por motivos que não temos o direito de discutir, não vem illustar nossa festa com a sua presença sempre respeitada, e sua palavra sempre ouvida com profundo acatamento. Eis ahi porque, como vice-presidente do Instituto, me cabe o difficil dever de substituir o nosso amado chefe nesta honrosissima cadeira.

Mas, surprendido á ultima hora com tão escabroso encargo, falhou-me de todo tempo para preparar discurso digno do assumpto e da vossa captivadora attenção. Não é facil tarefa fallar em vez de quem facilmente se impõe pela vastidão de sua scien. cia, pela robustez de seu esplendido talento, pela in. teireza de suas convicções inflexiveis. 
Pezadissima missão é tambem fallar da advocacia a advogados illustres e provectos como sois vós, meus estimados cullegas.

Entretanto, escravo do dever, comprehendi que me não era licito faltar á ordem do chefe, e eis-me aqui, obediente, e por isso mesmo digno da vossa benevolencia.

Que dizer-vos da nossa nubre e sancta profissão, que já não esteja escripto em vossa consciencia?

Nobre profissão, sim; e porque o é, representa um dos mais poderosos factores do poder mental das sociedades: foi por Cicero e Demosthenes que Roma e Athenas mais brilharam na historia social da humanidade; é por ella que ainda hoje Snyder, com os seus recentes Great speeches by great lawyers, e $\mathrm{Mu}-$ nier--Jolain, com sua La plaidoirie dans la langue française, exoram as corrompidas sociedades conternporaneas que não tenham como para sempre apagada a esperança em possivel cura moral. Sancta profissão, sim; e porque o é, tem, como todas as religiões, o seu evangelho immaculavel.

E assim como, senhores, cada religião, para solemnizar suas festas, faz lêr aos fieis o evangelho das suas crenças, dae-me venia para desobrigar-me da minha espinhosa tarefa de hoje relendo-vos o artigo que escrevi para servir de Introducção ao primeiro numero da nossa Revista. E' o nosso Evangelho, que escripto ha um quinquennio, já ficou esquecido de alguns, e ainda não se fez conhecido dos que vieram depois.

$\mathrm{E}$ terei assim construido inteiro o meu discurso de hoje. 
«Se a tanto nos forçasse a estafada rotina de bolorenta praxe, fastidiosa houvera de ser a enumeração - assim á guisa de apophtegmas forenses, como 'se deleitava em fazel-os Dupin, o velho-dos direitos e deveres do advogado, ou a anatomisação da positiva influencia moral, juridica e economica da advocacia sobre o progresso das sociedades antigas e modernas, ou a repetição do papel que representam os successores de Hyperides, o malicioso defensor da formosa Phrynéa, de Tito, o principe tão querido quanto antes fôra estimado patrono dos fracos e opprimidos, de Pélisson, o sagacissimo advogado de Fouquet, de Fourcroy, aquelle, que pleiteando por Saint-Agnan, teve esta felicissima phrase: A vida tem duas especies de inimigos: os homens $e$ as molestias, de Jonhson, Erskine ou de Mathew Hale, na terra de Blackstone, de Alvaro e Thomé Valasco ou de Caldas, na terra de D. Philippe, do preclarissimo Gustavo Hugo ou do estimadissimo Marini-Serra, lá onde depois brilharam os dous maiores jurisconsultos da Allemanha e da Italia: Savigny e Carrara. Molesto ainda fôra, porque entibia-se a imaginação si a vulgaridade serve-lhe de mira.

Quem não sabe, que assentando, por lei fatal da natureza humana, na Familia e na Propriedade a rayão social da Lei civil, é no advogado que summaria-se, como em Cicero se condensára a eloquencia juridico-romana, a sciencia architectada do Direito, que é precisamente a massa de que se compõe a mesma Lei, a que estreitamente se conchegam, como condição vital, a Familia e a Propriedade?

Quem não sente, si o honesto the é o ideal, como para Platão o universal era a unica substancia, que o advogado está para o Direito assim como Demosthenes para a eloquencia, Aristoteles para a philosophia, Homero para a poesia, Phidias para a arte, 
ou como Voltaire para a França, Humboldt para a Allemanha, Stuart Mill para a Inglaterra, Vico para a Italia? Imaginae antes philosophia sem logica, arte sem natureza, vapor sem calorico, musica sem som, fósseis em estado integro-organico ou morphologico, do que sociedade sem lei, lei coactiva sem direito, direito sem advogado.

A mais desastrosa das desharmonias sociaes, o contraste grosseiro por excellencia, é a contraposição entre o direito e a lei. A immutabilidade de um não raro oppõe laboriosa lucta á versatilidade da outra.

Aquelle, por ser institucionalmente absoluto, esculpiu, Phidias correctissimo, no grande livro do sentimento humano, a rutila formula republicana: Liberdade, Igualdade, Fraternidade-os tres degráos, na expressão de V. Hugo, da escadaria suprema; esta, espelho onde quotidianamente se reflectem as relatividades sociaes, oppõe, á Liberdade, a pena, á Igualdade, o censo, á Fraternidade, o imposto.

O direito, por que é, ainda na expressão do esculptural autor dos Actes et Paroles, insubmersivel, tem como equivalente a justiça, mas a lei, que ás vezes arroga-se petulancias anarchisddoras, creou a cousa julgada. A res judicata é, substancialmente, arma revolucionaria posta nas mãos da anarchia: effectua a deposição do logico suum cuique.

O direito é a manifestação physiologica da supremacia humana; é a sadia condensação da humanidade. Diz-se que os allemães punham a cabeça descoberta quando ouviam o nome de Cujacio: fascinação pelo mestre? não: irresistivel e perenne culto ao direito cujo sacerdote elle era. Se eu tivesse tido a feliz fraqueza de commungar na mesa das idéas divinas, diria que o direito é a mais sublime forma da divindade, 
e que, assim como se diz que Padre, Filho e Espirito Santo são as tres pessoas da Sanctissima Trindade, Liberclade, Igualdade e Fraternidade são as tres pessoas da Trindade social. Quem tem por si o direito dispõe da mais poderosa de todas as forças: é dominador no lar, na cidade, na patria, no mundo. Urbi et orbi. Mas vem o commercio eleitoral e faz o votante, o votante faz o legislador, o legislador faz a lei, finalmente a lei desfaz o direito. Frequente e terrivel sorites.

A lei, devendo ser invariavelmente remedio cuja virtude provê de forças a deficiencia individual, pode muitas vezes ser entidade morbida, perturbadora da saúde collectiva. Profundos espiritos houve, alguns mesmo argamassados de solida instrucção juridicaLeibnitz, por exemplo - que na lei mais não viam do que proximamente o antípoda do direito (I). Neste revés, quem destróe o morbo? quem salva o direito?

Se nova lei, moldada agora na verdade juridica, contrariando a negação scientifica operada pela primeira, restabelece a norma positiva do direito, bem vai. Lotificat cor hominis. A lei pode anniquilar a lei. Ha mesmo phenomenos mais curiosos. Referem tradições homericas, que no cerco de Troia, fôra Telepho, filho de Hercules, gravemente ferido pela lança de Achilles e que, consultado o oraculo de Apollo acerca do que convinha oppôr á gravidade da ferida, que, augmentava, e ás torturas da dôr, que cruciava o vencido mysiano, disse que só a propria lança do famoso filho de Peléa podia curar o mal.

(1) Não pareça haver cxaggeração no conceito, autorisado pelo seguinte trecho do famoso clrefe da escola monadologica: Nam si accurate rem consideramus omne jus civile magis facti est quam juris, quia probandum est non ex natura rerum sed ex historia seu facto.-Vid. Opera omnia, IV, 2 I I Nova Methodus discenda docendoque jurisprudentic, II, §7I. 
Mas si persiste a antagonia? si a lei faz contubernio manteúdo com o injusto? ou si, na melhor hypothese, foi a lei vasada nos moldes do justo, mas da reciproca manifestação de duas actividades livres nasceu um contraste nas relações de direito, operou-se, como diz Herzen em sua Physiologia da Vontade, a desorganisação funccional de dous centros parallelos? Quem o medico que ha de operar a reorganisação juridica, o reconstructor do edificio, que a lei esboroou no momento em que delle desapossou o direito?

O magistrado, dir-me-ia Bacon. Engano; ou melhor: inversão de posições. Primeiro, o advogado, e só depois deste, o juiz. Vêde em Roma, onde, desde Romulo, isto é, ab initio, estava prescripto que os advogados sahissem da classe dos que houvessem de exercer as funcções do sacerdocio ou da magistratura.

E que maior lustre para a advocacia do que os nomes dos primeirss adyogados romanos: Sexto Elio, cognominado o Cato, P. Mucio Scovola, Catão o Grande, M. Manilio, Bruto, Cicero, Publio Rufo, Julio Cesar, e outros, e muitos outros (1)? Não foi do seio da vida activa do Forum, onde as. luctas oratorias abriam franca estrada á investidura nos mais elevados cargos, que emergiram os maiores cidadãos romanos? Não era então corrente ser o Forum, le barreau, na traducção de Eug. Henriot (2), o viveiro das honras? Est corpus advocatorum seminarium dignitatum. Não temos a confissão de Cicero, de que não entrára naquella laureada carreira «senão por ambição, e que, si ainda lhe supportava os labores, era para melhor salvaguardar, pelo favor que tal carreira

(I) Montezuma, Rev. do Inst. dos Advogados Braz. I, 73.

(2) Mours juridiques et judiciaires de l'ancienne Rome, III, 99. 
proporcionava, as altas dignidades que nella adquirira $(\mathrm{I}) »$ ?

Quem não conhece estas verdades triviaes? Já não disseram, no remoto seculo $\mathrm{V}$, tão militarisado como cette fin de siècle, os imperadores Leão e Antemio, que não militam pela patria somente os que se fazem fortes nas espadas, nos escudos e nas couraças, mas tambem os advogados, porque estes, munidos da força da eloquencia, protegem os que soffrem, alimentam-lhes a esperança, defendem-lhes a vida $e$ os filhos (2)?

Qual de nós já esqueceu, do portentoso Cicero, a passagem em que, na vigorosa oração pro Murena, faz elle o parallelo entre o advogado e o general de exercito? O genial escriptor da Republica, o primeiro escriptor do mundo, no parecer de uma das maiores autoridades litterarias ( $\mathrm{I}$ ), produzindo, emulado pelas arrogancias de Catão, advogado do accusador Servio Sulpicio, acreditado jurisconsulto, a defesa de Murena, consul e homem de guerra, exprimiu-se assim: «Vigias, tu, á noite, a fim de te habilitares a responder aos teus clientes; elle, para fazer chegarem suas tropas a tempo no ponto que quer occupar; aquelle accorda ao primeiro canto do gallo, este, ao sum das trompas guerreiras; o primeiro, preparando e dispondo seus meios de accusação ou de defesa, o segundo, seu plano de batalha; um, velando na guarda de seus clientes, o outro, na das cidades e campos; elle sabe

(I) Forensem laborem, escrevia Cicero a Attico, antea propter ambitionem sustinui, nunc ut gratia dignitatem tueri possim.-Vid. Eug. Henriot, loc. cit.

(2) Nec enim solos nostro imperio militare credimus illos, qui gladiis, clypeis, et thoracibus nituntur: sed etiam advocatos militant namque patroni causarum, qui gloriosa vocis confisi minumè, laboriantium spem, jitam, et posteros defendunt-const. I 4 de advoc. div. jud. dier, 1854 .

(3) Villemain, E'tud. de litterat. anc. et étrang., pag. 48, ed. Di- 
como haver-se para se livrar do inimigo, tu, como proceder para affastar as aguas pluviaes; elle, exercitou-se na defesa das fronteiras, tu, na demarcação dos limites (I).»

Não temos no ouvido ainda o écho d'aquella phrase do mesmo Cicero, no tratado de officiis: "Cedant arma toge; concedat laurea linguve? 》

E de facto, durante longo tempo foi a toga, que sobre a espada, prevaleceu em Roma: attestam-o o poeta Bassus, a quem é attribuido o Carmen ad Pisonem:

Sic etiam jam tunc Cicerone vigente, Laurea facundis sesserant arma togatis-

e o emprego vulgar das sezuintes metaphoras: Mars forensis, togata militia, arma civica, arena fori, garrula bella, etc.

Nem por outro fundamento senão pela grande estima em que eram tidos os advogados, como os mais apurados cultores do direito, explica-se a passagem de Pomponio (fr. $2 \S 43$, de origine iuris): Turpe est patricio et nobili viro, et causas oranti, jus in quo versatur ignovare (2).

(I) "Vigilas, tu, de nocte, ut tuis consultoribus respondeas, ille, ut «eo quo intendit mature cuim exercitu perveniat; te gallorum, illum bucci"narum cantus exsuscitat; tu actionem instituis, ille aciem instruit; tu "caves ne consultores tui, ille ne urbes aut castra capiantur; ille tenet et "scit ut hostium copio, tu, ut aquo pluvice arceantur; ille exercitatus est "in propugnandis finibus, tu in regendis."

"Si dans le métier de la parole, diz La Bruyère, il y a plus de risques que dans celui de la guerre, auquel il ressemble en quelque chose, en revanche la fortune $y$ est plus rapide». (Chap. I4).

(2) O valor do estudo do direito está nitidamente impresso n'aquelle texto, tão interessante, que não podemos nos furtar ao prazer de transcrevel-o. «O proprio Servio merece logar distincto entre os advogados celebres. Occupava elle a primeira fila entre os oradores, ou pelo menos a segunda, preferindo-lbe Cicero. Refere-se, segundo Marco Julio, que tendo ido consultar Quinto Mucio acerca de uma causa que interessava a un de seus amigos, Servio não logrou comprehender o que Mucio havia decidido; que inqueriu-o segunda vez, e não comprehendeu ainda a resposta do jurisconsulto; pelo que foi-lhe por Quinto Mucio feita esta reprimenda: "Torpe é a um patricio, nobre, e 
$\mathrm{O}$ que ha de mais sabido do que, ha quasi dous seculos, disse D'Aguesseau: que a ordem dos advogados é tão antigà como a magistratura, tão nobre como a virtude, tão necessaria como a justiça ( $\mathrm{r}$ )?

Eis porque, incumbido, pela esmagadora benevolencia dos meus illustres collegas do Instituto, do primeiro artigo de sua primeira Revista, afigurou-se-me que fastidioso fôra escrever mais uma pagina sobre a historia e missão da advocacia, esta sancta religião a cujo culto votei todas as forças do meu minguado talento e as melhores energias da minha afanosa actividade.

De resto, para fazer-me echo do celebre cantor de Mazeppa.

This too sinks after many a league

Of well sustain'd but vain tatigue (2).

Como, pois, desempenhar-me?

Houvera eu accumulado os creditos litterarios do grande desventurado Vieira de Castro, e poderia aqui deixar, parodiando-lhe a primeira phrase do seu famoso discurso sobre a Caridade, a minha ultima linha: - E o meu artigo está feito.

E estaria, se não me estivessem duas paixões, bem impulsionadas ambas, estimulando alguns conceitos mais, que vou traduzir em dupla exhortação ao Instituto.

Pela primeira incito-o a vehemente insurreição contra os diffamadores da advocacia, que os ha mui-

advogado, ignorar o direito no qual devia ser versado.» Magoado por esta especie de affronta, applicou-se Servio ao estudo do dircito civil, e procurou as licções de muitos dos jurisconsultos sobre que temos fallado... Deixou cerca de 180 volumes dos quaes muitos nos restam ainda."

(I) Carrara, Il passato, il presente e l'avvenire degli avocati, Intr.

(2) Byron, Mazeppa, II, 12. "Tambem elle afinal succumbe após longo caminho de vã fadiga corajosamente sustentada.» 
tos, torpes invejosos uns, exploradas victimas, outros, dos togados espurios. No templo da nossa religião ha tambem mercadores. Pois bem: da acção collectiva do nosso notabilissimo e independente ministerio pode vir, e é nosso dever procurar que venha, a larga, a inteira, a moralisadora nobilitação d'este officio, que é a guarda da Familia e da Propriedade, isto é, do Direito.

E nada ha mais facil. Abra cada qual, no livro de sua consciencia, duas paginas alvissimas, e n'ellas inscreva, como estrellas rutilantes de explendor, estas duas unicas palavras, solido compendio das mais rigidas prescripções moraes: Estudo e Honra.

Se da prolifica imaginação de Moysés vem o lêr-se na biblia que Deus é o alpha e o ómega da creação, não me levem á conta de louçania, ou lavor pedante, paraphrasear o mais fecundo creador de lendas: Estudo e Honra são o alpha e o ómega da advocacia.

Estudar o direito, como Servio Sulpicio, para applical-o na defesa alheia, que melhor meio de desmentir a ataxia romantica do languido Bernardin de St. Pierre:- Partout où il y a beaucoup d'avocats et de médecins, les procès et les maladies sont en plus grand nombre quailleurs?!

Parva necedade! Imaginae quanta paz, que profunda paz reinaria onde não houvesse advogados nem medicos: não haveria pleitos, mas as molestias possessorias matariam as industrias; não haveria receitas, mas o cemiterio alargaria a propria area. Verdadeira paz de Varsovia. Até faz lembrar certo telegramma passado em certo estado de certa Republica militar: "Casas fechadas. Conmercio paralysado. Reina inteira ordem e completa tranquilidade» Em ninha Miscellanea collei aquella joia politico-litteraria, e caudei-lhe esta 
paraphrase: "Cemiterio da Consolação, à meix noite. Silencio profundo.»

Estudar o direito conscienciosamente, demoradamente, apaixonadamente, fazer d'elle a arma unica nos combates judiciarios - que victoria! que pregão lançado aos tolos impertinentes, como aquelle juiz do seculo XVI, de Harlay, celebre pela sua Harlocana, picante collecção de anecdotas forenses:-Rien n'est plus aisé à juger qu'une affaire quand elle se présente dans les tribunaux; quand les avocats ont parlé, rien n'est plus difficile!

Estupida ironia! e que vontade faz de rir o topar assim um Marcial vestido com a toga de magistrado! E quantos ha que do advogado fizeram o alvo da suas biliarias expansões! Porque? exclusivamente por isto: porque o advogado aponta-lhes quotidianamente as licções juridicas que elles esqueceram por força de negação congenita, de aberração organicoinstitucional. Abre-se-vos corrente azo para uma citação latina? imperdoavel peccado! quem mais supporta a dulcissima lingua de Virgilio (I)? Vosso erudito espirito acha pertinente a invocação de um, dous, dez escriptores? A rememoração de um facto juridico, de um episodio historico? o novo Marcial de logo tenta ridiculisar-vos, e; insufflando-se até macaquear Dumoulin, aquelle que de si dizia-ego, qui omnes doceo et a nemine doceri possum-repeteria, si soubesse, o epigramma das tres cabras, do espirituoso amigo de Plinio, o moço (2). Gostaes de ser, no

(I) Lembro-me de ter lido em um jornal do Rio, como justificação da violenta aposentadoria do conselheiro Justino de Andrade, muito amigo de citar textos romanos, dizia o articulista, não haver hoje quem possa apreciar a leitura de Virgilio ou de Cicero em latim! Como é atrevida a ignorancia!

Com certeza aquelle litterato é dos novos...

(2) Que Racine, nos Plaideurs, plagiou assim:

...Avocat, il s'agit d'un chapon,

Et nom pas d'Aristote et de sa.Politique. 
estylo, paciente e esmerado lapidario? sentis proveitoso recreio em tornear a phrase, enfronhando o pensamento nos atavios de deleitavel purismo? sereis logo tosquiado pela baixa inveja dos escrevinhadores de carregação (I).

Parallelamente, deve correr a honestidade. Ha quantos seculos deram do advogado a conhecida definição-VIR BONus, isto é, homem honrado, dicendi peritus? A chaga que mais purulentamente pode abrir-se na nossa profissão é essa, que chamarei pirataria forense, e que infelizmente ás vezes lastra na baixa praia da advocacia miuda. Mercantilismo repulsivo, a vena. lidade forense é o ultimo periodo da decomposição social. Unamo-nos, pois, em guerra, desapiedadamente continua, contra aquelles a quem, já lá vão seculos, referia-se Pamphilo Saxo:

Per fora clamọsas exercent improba lites, ou Michael:

\section{Ventosaque verba \\ Venali jactata foro.}

Esta é a primeira exhortação. A outra, vamol-a antes segredar, bem baixinho, do que arremessal-a tão sonante e livremente como fizemos com aquella. E' ainda um pacto de guerra-guerra de morte, sem tregoas, a todo custo: guerra á politica nos arraiaes do Instituto. Entre a politica e o direito não ha contacto possivel. $\mathrm{Na}$ politica ama-se ou odeia-se muito, disse Cavour; no direito não se conhece o odio. $\mathrm{Na}$

(i) Entretanto, quão bem applicam-se, aos advogados, as seguintes linhas de um dos mais famosos professores contemporaneos. E' só lér arra. zoado onde se lê liçcrõo. "La lezione de un professore è il suo campo di battaglia, $e$ in essa e riposto il suo trionfo: qualunque disciplina sinsegni, anche pratica e sperimentale, la parola può colorirla, la verità può infocarla, perchè ogni fenomeno ha il suo lato poetico ed ogni cosa ha il suo splendore.» Cogliolo, Melanconie Universitaries p. 133 . 
politica não ha lealdade; no direito o que não fôr leal não medra. A impostura politica falla em nome do povo, como a impostura religiosa falla em nome de Deus (I); o direito falla sempre em nome da justiça, que é a propria verdade. Nós somos as sentinellas dos Tribunaes; pois bem - tenhamos sempre viva no espirito esta sentença, caustica, mas verdadeira, vergonhosa, mas real, de um estimado professor italiano: Quando a politica entra nos tribunaes, qualquer que seja a mão que a introduz, qualquer que seja o motivo por que entra, a justiça vê-se constrangida a fugir (2)

Cá fora sim: quem tiver alma grande, crenças generosas, combata, derrame até a ultima gotta de sangue pela unica politica harmonica com a superioridade do homem - pela Republica; mas pela Republica verdadeira, a genuina, pela Republica que sonhámos todcs os que queremos o Brasil grande, o Brasil respeitado pelo mundo inteiro».

Dr. $\mathfrak{E} \circ a \tilde{o}$ OTonteiro.

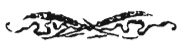

(I) Bentham, Organ. Judic. cap. 18.

(2) Manfredini, Progr. del corso di Proc. Cav. pag. 266. 